\title{
REFLEXÕES SOBRE O ESTÁGIO DOCENTE SUPERVISIONADO EM NÍVEL DE POS-GRADUAÇÃO A LUZ DA TEORIA DA COMPLEXIDADE
}

\author{
REFLEXIONES SOBRE EL MAESTRO ETAPA \\ SUPERVISADO EN POSTGRADO NIVEL LA LUZ DE LA TEORÍA DE LA \\ COMPLEJIDAD
}

\section{REFLECTIONS ON STAGE TEACHER \\ SUPERVISED IN POST- GRADUATE LEVEL THE LIGHT OF THE THEORY OF COMPLEXITY}

\author{
Cibele Galvão SANTOS ${ }^{1}$
}

\begin{abstract}
RESUMO: este artigo traz um recorte do trabalho de dissertação de mestrado, apresentado ao programa de Pós-graduação Stricto Sensu Mestrado e Doutorado em Educação, da Universidade Católica de Brasília (UCB/DF) e tem como tema: Estágio Docente Supervisionado em nível de pós-graduação e Complexidade. Aborda parte dos resultados da dissertação de mestrado e traz como objetivo geral divulgar os resultados da pesquisa. De forma específica pretende contribuir com novas discussões sobre o tema; divulgar a voz dos estudantes que participaram da pesquisa; e incentivar a construção de novos trabalhos. Para elaboração do trabalho, em sua abordagem qualitativa, foram utilizadas mais de uma metodologia, entre elas: a pesquisa bibliográfica, e a análise de conteúdo. A realização desse artigo justifica-se por ser um campo, ainda pouco estudado, carente de observações a seu respeito. Conclui-se o estágio docente supervisionado em nível de pós-graduação possui uma dinâmica relacional de natureza complexa. Sugere-se ao final, um caminho para as questões de dificuldades apresentadas pelo cenário pesquisado como, por exemplo, o trabalho integrado e integrador dos sujeitos, a abertura, a flexibilidade e a contextualização do conhecimento.
\end{abstract}

Palavras-chave: Estágio Docente. Pós-graduação. Complexidade.

RESUMEN: en este trabajo se presenta una aproximación a la tesis de maestría, presentado en el programa de postgrado stricto sensu Masters y Doctorado en Educación de la Universidad Católica de Brasilia (UCB / DF) y tiene como tema: Supervisado posterior a nivel de Enseñanza graduación y Complejidad. Direcciones de los resultados de tesis y tiene como principal objetivo difundir los resultados de la investigación. Específicamente pretende contribuir a los debates sobre el tema; difundir la voz de los estudiantes que participaron en la encuesta; y fomentar la construcción de nuevas obras. Para desarrollar este trabajo, en su enfoque cualitativo se utilizaron más de una metodología, que incluye: una búsqueda en la

\footnotetext{
${ }^{1}$ Mestre em Educação pela Universidade Católica de Brasília (UCB/DF/Brasil). Pesquisadora do Grupo de pesquisa ECOTRANSD - Ecologia dos Saberes, Transdisciplinaridade e Educação. Professora da Fundação Antares de Ensino Superior, Pós-Graduação, Pesquisa e Extensão (FAESPE/GO/Brasil) Email: gsantoscibele@gmail.com. 
literatura, y el análisis de contenido. La realización de este artículo se justifica porque se trata de un campo, sin embargo, poco estudiada, carente comentario sobre este informe. El maestro supervisado a nivel de postgrado cuenta con una dinámica de relación de naturaleza compleja Se concluye. Se sugiere al final, una forma de que las dificultades de cuestiones planteadas por el escenario estudiado, por ejemplo, el trabajo integrado e inclusivo de los sujetos, la apertura, la flexibilidad y la contextualización del conocimiento.

Palabras clave: pasantía maestro, máster, complejidad

\begin{abstract}
Masters dissertation, presented to the Post-graduate program stricto sensu Masters and Doctorate in Education at the Catholic University of Brasilia (UCB / DF) and has as its theme: Supervised Teaching-level post graduation and Complexity. Addresses of the dissertation results and has as main objective to disseminate the results of research. Specifically intends to contribute to further discussions on the subject; spread the voice of the students who participated in the survey; and encourage the construction of new works. To develop this work, in its qualitative approach were used more than one methodology, including: a literature search, and content analysis. The realization of this article is justified because it is a field, yet little studied, lacking comment on this report. The teacher supervised at postgraduate level features a relational dynamics of a complex nature It is concluded. It is suggested in the end, a way for the difficulties of questions submitted by the scenario studied, for example, the integrated and inclusive labor of subjects, openness, flexibility and contextualization of knowledge.
\end{abstract}

Key words: Stage Teacher . Graduate School. Complexity.

\title{
Introdução
}

Este artigo é um recorte de uma dissertação de mestrado apresentada ao programa de Pós-graduação stricto sensu Mestrado e Doutorado em Educação, da Universidade Católica de Brasília (UCB/DF), no mês de agosto de 2011 e traz como tema: o Estágio Docente Supervisionado em nível de pós-graduação.

Por meio das pesquisas desenvolvidas, foi possível perceber que o tema, apesar de ser abordado em nível de educação fundamental, de ensino médio e de graduação, encontrava-se um tanto obscuro e carente de aprofundamento em nível de pós-graduação. Esse fato fundamentou as justificativas científicas e sociais para a construção da pesquisa. Em âmbito pessoal, esse trabalho justifica-se pela vontade de esclarecer os acontecimentos ocorridos em campo de estágio docente supervisionado, em relação à práxis, não tão coerente com as teorias estudadas na graduação.

Cabe esclarecer que nesse artigo, devido a extensão da dissertação de mestrado e o 
tempo e espaço disponibilizados para a organização desse texto, somente serão apresentados uma parte do todo e alguns dos resultados e discussões obtidos com a realização da investigação ${ }^{2}$.

As discussões sobre estágio docente supervisionado em nível de pós-graduação emergiram com o objetivo maior de investigar, à luz da Complexidade, a dinâmica relacional estabelecida no desenvolvimento das práticas de ensino docente supervisionado, de acordo com a percepção de alunos estagiários do curso de Mestrado em Educação, de uma Instituição de Ensino Superior particular, localizada no Distrito Federal.

Os monitores podem escolher entre dois processos de monitoria: o Grupo de Aprendizagem - GA e o Grupo de Pesquisa - GP. O foco do trabalho foi direcionado para o GP, pois os procedimentos do GA são administrados e orientados diretamente pela coordenação do curso de Pedagogia, na graduação e não fazem parte dos objetivos desta pesquisa.

O GP fica a cargo da coordenação do Mestrado em Educação, situada no campus da pós-graduação e consiste em uma oportunidade para que o aluno mestrando possa entrar em contato direto com diversos projetos de pesquisa de acordo coma linha de pesquisa que ele escolheu.

O programa de pós-graduação stricto sensu em Educação da IES pesquisada, na época do desenvolvimento do trabalho de dissertação de mestrado, ofertava duas áreas de concentração: Políticas e Administração Educacional e Ensino Aprendizagem. A primeira dedica-se à investigação de questões sócio-históricas com destaque para os aspectos políticos, econômicos e sociológicos da educação. A segunda envolve uma análise epistemológica das dimensões fundamentais da educação, do currículo e do processo de ensino e de aprendizagem.

Em âmbito específico a dissertação pretendeu, entre outros, definir o estágio supervisionado e suas características de acordo com a legislação vigente e propor uma visão interativa entre as relações estabelecidas no desenvolvimento das práticas de ensino docente em nível de pós-graduação, vivenciadas por estudantes.

Dessa maneira, foram entrevistados sete estudantes, monitores do curso de Mestrado em Educação, conhecidos pelos demais estudantes da graduação em Pedagogia como

2 Ver: Sistema de publicação eletrônica de teses e dissertações, Universidade Católica de Brasília (UCB), dissertação de mestrado com o título Estágio docente supervisionado e Complexidade: uma pesquisa em nível de Pós-Graduação. Disponível em: 
"estagiários do mestrado". Os estudantes monitores selecionados possuíam, entre outros requisitos, a titulação em licenciatura, a matrícula regularmente instituída e o término das atividades de monitoria.

A monitoria consistia em um trabalho voluntário desenvolvido na graduação da Instituição de Ensino Superior (IES) pesquisada. Os monitores são estudantes regularmente matriculados nos cursos de mestrado e/ou doutorado em Educação, que de forma voluntária e não compulsória, se oferecem para realizar as práticas de estágio docente no curso presencial de graduação em Pedagogia.

A exceção, à regra do voluntariado e da não compulsoriedade, diz respeito apenas aos estudantes que realizam o mestrado por meio da bolsa de estudos ofertada pela Coordenação de Aperfeiçoamento de Pessoal de Nível Superior (CAPES). Ao assinarem os papéis da bolsa, já são informados da necessidade da realização das práticas de estágio docente supervisionado de forma obrigatória.

O estágio, a luz da Lei $\mathrm{n}^{\circ}$ 11.788/08, denominada Lei do Estágio, que vigora desde 26 de setembro de 2008, é conceituado como ato educativo escolar, o qual deverá ser supervisionado, desenvolvido no ambiente de trabalho. Essa ação educativa tem por objetivo preparar o educando para o trabalho (BRASIL, 2008).

Esse trabalho aborda o estágio de licenciatura, em nível de pós-graduação o qual, além da Lei de Estágio, é regulamentado de forma mais específica pela Portaria $n^{\circ} 64$ de 18 de novembro 2002, que trata do Programa de Fomento à Pós-Graduação (PROF).

Nesse contexto, a teoria da Complexidade foi a semente, cheia de luz e preciosa, que ao ser lançada nas terras férteis do estágio floresceu como árvore frondosa, a qual se apresentou imbricada, das raízes aos frutos, em toda a dinâmica relacional estabelecida no desenvolvimento das atividades práticas observadas.

O sujeito interpreta e reconstrói a realidade à sua imagem e semelhança, de acordo com suas possibilidades estruturais, mas, ao mesmo tempo, é influenciado pelas ideias e relações com o outro. É um saber relacional e contextual gerado numa ecologia de pensamentos e ações que surgem em função das circunstâncias criadas nos ambientes de aprendizagem (MORAES, 2003).

Por esse viés, educador e educando se encontram estruturalmente acoplados de forma a participarem de um contexto de fluxos interativos entre si, durante os processos de ensino e aprendizagem. Isso ocorre nas conversações, nas percepções que ambos extraem do meio e 
uns dos outros e que têm de si mesmos, na vivência dos próprios processos de ensino e de aprendizagem.

Assim, professor-aluno, aluno-professor, inseridos em um contexto, se influenciam mutuamente, constroem e reconstroem o conhecimento formando uma grande espiral, uma dinâmica relacional, na qual ambos interagem, vivem e convivem.

A partir de sua abordagem qualitativa e exploratória, a elaboração da dissertação de mestrado foi realizada por meio da utilização de mais de um caminho metodológico, entre eles: a pesquisa bibliográfica; a técnica de entrevista semiestruturada e a análise de conteúdo.

Este artigo tem como objetivo maior divulgar os resultados desse trabalho de dissertação de mestrado para contribuir com o maior número de pessoas que tenham interesse no tema de estágio docente supervisionado. O olhar para o nível de pós-graduação é uma inovação, por isso, de forma específica, pretende-se: contribuir com novas discussões sobre o tema; divulgar a voz dos estudantes que participaram da pesquisa; e incentivar a construção de novos trabalhos.

\section{O estágio supervisionado}

No Brasil, a temática do estágio supervisionado é tratada de forma ampla e atualmente essa temática se encontra disciplinada por meio da Lei $\mathrm{n}^{\circ} 11.788 / 08$ a qual, dispõe sobre o estágio de estudantes, revoga legislações anteriores e determina as ações das instituições educacionais.

A Lei ${ }^{\circ} 11.788 / 08$, denominada Lei do Estágio, vigora desde 26 de setembro de 2008. Esta legislação proporciona maior segurança nas relações jurídicas do estágio, esclarece quem pode ofertar o estágio, a carga horária e as férias. Aborda também a definição, a finalidade, os objetivos e os requisitos necessários ao desempenho do estágio.

O Ministério do Trabalho e Emprego (MTE), com o objetivo de orientar estudantes e instituições de ensino, organizou A Nova Cartilha Esclarecedora sobre a Lei do Estágio ${ }^{3}$, um material distribuído gratuitamente em formato impresso ou via internet. Essa Cartilha foi publicada em 24 de dezembro de 2008. Além da Lei na íntegra, o texto apresenta setenta perguntas e respostas relacionadas ao sistema de educação nacional e ao desenvolvimento do estágio.

$\mathrm{O}$ artigo $1^{\circ}$ da Lei $\mathrm{n}^{\circ} 11.788 / 08$ define o estágio como:

\footnotetext{
${ }^{3}$ Disponível em: <http://www.mte.gov.br/politicas_juventude/cartilha_lei_estagio.pdf>. Acesso em: 14.Fev.2011. TERCEIRO INCLUÍDO ISSN 2237-079X NUPEAT-IESA-UFG, v.5, n.1, Jan./Jun., 2015, p. 98-122, Artigo 85102 Dossiê ECOTRANSD: Ecologia dos saberes e Transdisciplinaridade
} 
Art. $1^{\circ}$ Estágio é ato educativo escolar supervisionado, desenvolvido no ambiente de trabalho, que visa à preparação para o trabalho produtivo de educandos que estejam freqüentando o ensino regular em instituições de educação superior, de educação profissional, de ensino médio, da educação especial e dos anos finais do ensino fundamental, na modalidade profissional da educação de jovens e adultos. (BRASIL, 2008).

Existem estágios supervisionados nos diversos níveis de educação. Cada nível, além de seguir a legislação federal vigente, possui normatização específica. O estágio docente supervisionado em nível superior foi regulamentado pela CAPES, em 1999, por meio do Ofício Circular no 28/99/PR/CAPES. Este ofício instituiu o estágio de docência na graduação (VIEIRA; MACIEL, 2010).

Baseada nessa regulamentação, a CAPES regulamentou, em nível de pós-graduação, o estágio de docência por meio da Portaria $\mathrm{n}^{\mathrm{o}} 64$ de 18 de novembro 2002, que trata do Programa de Fomento à Pós-Graduação (PROF). Este programa tem como objetivo permitir o atendimento adequado das Instituições de Ensino Superior (IES) para alcançarem, com qualidade, a formação de recursos humanos. Essas determinações deverão constar no planejamento institucional.

O PROF trata especificamente do estágio docente supervisionado em nível de pósgraduação e traz em seu artigo 22:

Art. 22. O estágio de docência é parte integrante na formação do pósgraduando, objetivando a preparação para a docência, a qualificação do ensino de graduação, e será obrigatório para todos os bolsistas do PROF, obedecendo aos seguintes critérios:

I - para o programa que possuir os dois níveis, mestrado e doutorado, a obrigatoriedade ficará restrita ao doutorado;

II - no programa que possuir apenas o nível de mestrado, será obrigatória à [sic] realização do estágio;

III - as instituições que não oferecerem curso de graduação deverão associar-se a outras instituições de ensino superior para atender as exigências do estágio de docência;

IV - o estágio de docência com carga superior a sessenta horas poderá ser remunerado a critério da IES, vedada a utilização de recursos repassados pela CAPES;

V - a duração mínima do estágio de docência será de um semestre para o mestrado e dois semestres para o doutorado;

VI - compete à Comissão de Bolsa/CAPES, registrar e avaliar o estágio de docência para fins de crédito do pós-graduando, bem como a definição quanto a supervisão e o acompanhamento do estágio;

VII - o docente de ensino superior que comprovar tais atividades ficará dispensado do estágio de docência;

VIII - as atividades do estágio de docência deverão ser compatíveis com a área de pesquisa no programa de pós-graduação, realizada pelo pósgraduando (BRASIL, 2002). 
Além do Ministério do Trabalho e Emprego (MTE) e do Ministério da Educação (MEC), no Brasil, a CAPES colabora com a regulamentação a respeito do estágio docente supervisionado. Em relação ao estágio de docência em nível de pós-graduação, a legislação deixa claro que o estágio visa preparar o docente para o ensino na graduação.

Porém, as práticas de ensino docente são obrigatórias apenas para os estudantes beneficiados com o programa de bolsas oferecido pela CAPES. Em caso de instituições que possuem mestrado e doutorado, a obrigatoriedade de fazer o estágio docente supervisionado se restringe ao doutorado.

O estágio supervisionado é uma atividade que proporciona ao indivíduo que o realiza a oportunidade de descobrir se escolheu a profissão que corresponde a sua verdadeira aptidão (BIANCHI, Ana; ALVARENGA; BIANCHI, Roberto, 2005).

O processo de estágio está presente em diversos campos de ensino, tanto voltado aos cursos de Bacharelado, como aos cursos de Licenciatura. Cada área apresenta características próprias e, os trabalhos de estágios são planejados com base nelas:

O estágio em licenciatura é muito especial e diferencia-se totalmente daquele destinado aos cursos de Bacharelado, pois se direciona para futuros educadores, [...] A formação do professor é algo muito especial. Da aplicação competente de seu conhecimento profissional vai depender o futuro de todos os que hoje, no papel de aprendizes, participarão do processo educativo (BIANCHI, Ana; ALVARENGA; BIANCHI, Roberto, 2005, p. $5)$.

Pimenta (1995) afirma que o estágio é um componente do currículo que não se configura como disciplina, mas como atividade. A atividade teórico-prática de ensinar constitui o núcleo do trabalho docente. Referindo-se à formação do assistente social, Buriola (2009) salienta que o estágio é uma atividade que não pode ser dispensada:

[...] o estágio supervisionado é imprescindível na formação do assistente social. Este é concebido como uma situação-processo de ensinoaprendizagem. É o locus apropriado onde o aluno desenvolve a sua aprendizagem prática, o seu papel profissional, a sua responsabilidade, o seu compromisso, o espírito crítico, a consciência, a criatividade [...] (BURIOLA, 2009, p. 83).

Ainda de acordo com a mesma autora, o estágio supervisionado, na visão de docentes, supervisores e alunas pesquisados por ela, descortina um panorama de relações históricas, dialéticas e contraditórias estabelecidas em meio ao desenvolvimento das práticas de ensino- 
aprendizagem (BURIOLA, 2009).

Nesse contexto, o estágio supervisionado pode ser compreendido como um processo de fundamental importância na formação do indivíduo. Proporciona, além do conhecimento prático, a oportunidade de aprimoramento pessoal e profissional.

$\mathrm{Na}$ IES pesquisada o estágio docente supervisionado é denominado de monitoria. A abertura das inscrições para uma vaga na monitoria é comunicada via internet, por meio de edital afixado no mural da Universidade, em sala de aula por alguns professores ou mesmo via conversa informal entre alunos do curso de Mestrado. Os alunos mestrandos, desde que sejam regulares no curso, podem participar do processo de monitoria de duas formas: a voluntária e a obrigatória.

A primeira pode ser solicitada diretamente pelo aluno à secretária da coordenação do curso Stricto Sensu Mestrado em Educação. A segunda será comunicada aos mestrandos bolsistas da Capes no momento em que assinarem os papéis referentes à bolsa. Eles são informados da obrigação de realizar a monitoria pelo tempo de dois semestres. Os monitores podem escolher entre dois processos de monitoria: o Grupo de Aprendizagem - GA e o Grupo de Pesquisa - GP.

O processo de solicitação para a participação da monitoria é simples e não requer o pagamento de taxas de inscrição. Os participantes voluntários ou bolsistas, ao final de suas práticas, têm direito ao Certificado de participação como monitores em Experiência Docente no curso de Pedagogia.

Após a regulamentação na coordenação do curso de Mestrado em Educação, os monitores entram em contato com os professores doutores para as devidas orientações referentes ao desempenho das práticas em campo. Cada professor doutor é livre para orientar o seu monitor de acordo com a sua disciplina na graduação.

\section{Os caminhos metodológicos}

$\mathrm{Na}$ dissertação, os procedimentos metodológicos foram utilizados para identificar, compreender e analisar a dinâmica relacional que ocorreu no processo de estágio docente supervisionado a partir da percepção de estudantes estagiários, das suas relações tecidas com os outros sujeitos pertinentes a este cenário e com o ambiente foram apoiados nos trabalhos de diversos autores. Devido ao tempo e espaço aqui permitidos, não será possível descrever 
todos. Porém, de forma ampla, cabe destacar:

a) Maria Cândida Moraes, doutora e pesquisadora na seara da Complexidade e da Transdisciplinaridade, com diversos trabalhos publicados no Brasil e no exterior, além de orientadora da dissertação de mestrado, contribuiu como autora trazendo, juntamente com o autor e pesquisador José Armando Valente, o método de pesquisa da Complexidade que foi o embasamento maior de todo o trabalho. Segundo esse método, a pesquisa deve trabalhar com os princípios da incerteza, com a não linearidade dos fatos e acontecimentos e ser aberta ao inesperado. Mais que isso, deve ser aberta:

b)

[...] à intuição, à imaginação e a criatividade. Enfim, um método de acordo mais com a dinâmica da vida e que não mais considere a realidade como imutável, estável ou fixa. Busca-se um método que não despreza a subjetividade, a afetividade, nem as considere como fontes de erro (MORAES; VALENTE, 2008, p. 53-54).

c) $\mathrm{O}$ enfoque de caráter qualitativo emergiu apoiado nas ideias e concepções de Alda Judith Alvez-Mazzotti, psicóloga e doutora em Psicologia da Educação, e de Fernando Gewandsznajder, filósofo e pesquisador, que trazem a visão de que as pesquisas qualitativas são caracteristicamente multimetodológicas, isto é, usam uma grande variedade de procedimentos e instrumentos de coleta de dados (ALVES-MAZZOTTI; GEWANDSZNAJDER, 1998).

d) O caráter exploratório do tratamento de dados, pelo viés qualitativo, fez-se presente devido à investigação ocorrer in loco segundo Maria Isaura Pereira de Queiróz (1992). A pesquisa exploratória tem por objetivo o conhecimento do objeto tal como se apresenta no contexto onde se encontra, pressupõe que o comportamento humano é mais bem compreendido no meio em que ocorre.

As metodologias inspiradas na Complexidade e no enfoque qualitativo de pesquisa embasaram, entre outros princípios, a concepção de que sujeito e objeto pesquisado são codependentes, não são linearmente separados entre si. O pesquisador participa da realidade e do mundo do objeto pesquisado e sujeito e objeto estão intimamente imbricados (MORAES; VALENTE, 2008).

e) A pesquisa bibliográfica foi amparada pela maestria das autoras Marina de Andrade Marconi e Eva Maria Lakatos, segundo as quais a bibliográfica, ou de fontes secundárias, abarca a bibliografia já tornada pública (MARCONI; LAKATOS, 1996). 
O trabalho de dissertação utilizou-se tanto de fontes primária como de fontes secundárias, mesclando ambas em um tecido em conjunto com os demais métodos que resultaram assim, em uma colcha com diversos retalhos de informações, de relações e de afetividade em forma de trabalho de pesquisa.

f) A técnica de entrevista semiestruturada foi embasada nas teorias da autora Verena Alberti (2005), pesquisadora do Centro de Pesquisa e Documentação de História Contemporânea do Brasil (CPDOC) que, por sua experiência com a realização de diversos trabalhos, contribuiu com a pesquisa na elaboração do trabalho de campo. Fundamentou a construção da coleta de dados com base na entrevista aberta, semiestruturada, organizada por meio de um roteiro criterioso o qual, foi aplicado com a utilização do recurso do gravador portátil que proporcionou maior segurança e fidedignidade aos dados coletados.

g) Devido a profundidade de leitura que a sua execução proporciona ao material adquirido em campo, a análise de conteúdo, trazida pelos escritos de Laurence Bardin (2009), foi o conjunto de técnicas de análise das comunicações utilizada para o tratamento dos dados coletados. Esse método consiste em:

[...] a análise de conteúdo aparece como um conjunto de técnicas de análise das comunicações que utiliza procedimentos sistemáticos e objetivos de descrição do conteúdo das mensagens. [...] $\mathrm{O}$ analista é como um arqueólogo. Trabalha com vestígios (BARDIN, 2009, p. 41).

Ela foi especialmente pensada para a realização das análises das falas dos estudantes entrevistados, após as transcrições porque além de ser um procedimento logicamente ordenado de descrição, inferência e interpretação da fala, da comunicação dos entrevistados, trabalha as significações com a intenção de buscar aquilo que está por trás das palavras.

\section{Passo a passo da pesquisa}

O passo a passo da pesquisa foi permeado de ações previamente planejadas. Porém, por se tratar de uma pesquisa centrada na Complexidade, como teoria fundamental e norteadora de todo o projeto, os caminhos percorridos ora se apresentaram lineares e objetivos, ora se apresentaram abertos, flexíveis e subjetivos e, muitas vezes, um pouco de tudo isso ao mesmo tempo. 
E nem poderia ser diferente. De acordo com a teoria da Complexidade, que traz em si o uno e o múltiplo, a ordem, a desordem e a organização (MORIN, 2007; 2010b), essa pesquisa surgiu pelo meio, pela vontade de esclarecer os acontecimentos em campo de trabalho, em relação à práxis de estágio supervisionado, não tão coerente com as teorias estudadas na graduação. Ela surgiu em meio aos trabalhos de estágio supervisionado da própria pesquisadora, antes mesmo da criação do problema de pesquisa.

Em primeiro lugar, foi a observação in loco que se manifestou. Após isso, vieram os estudos das teorias e dos respectivos autores e, somente então, foram surgindo os objetivos, a metodologia e, quase que por último, a clareza do problema de pesquisa.

É certo que o problema de pesquisa sempre esteve presente, já que ele é parte integrante de quem o pesquisa. Como afirma Moraes (2008), o indivíduo influencia e é influenciado pelo meio em que vive e se desenvolve, moldando-o, coletivamente, de maneira que nada existe separado do próprio processo de viver/conviver. O compartilhar linguagens, pensamentos e emoções a partir de um processo dinâmico de relações que se forma e se transforma do entrelaçamento das vivências humanas, de interações, de valores, de significados é inerentes à vida.

É importante ressaltar que o trabalho de dissertação, apesar de possuir fases bem definidas, não foi confeccionado de forma pontual e linear, mas sim uma dinâmica não-linear como se apresenta. Aqui se encontra a ponta do iceberg, uma parte representativa do todo, em forma de texto escrito e organizado de maneira didática.

Os procedimentos metodológicos trouxeram em si a incerteza, a confusão, a desordem e, ao mesmo tempo, as certezas provisórias, a organização temporária e a ordem não permanente. Muitos passos foram desenvolvidos de forma simultânea e outros que tradicionalmente deveriam ser os primeiros, tornaram-se os últimos.

A realização do trabalho de campo da pesquisa em um primeiro momento, utilizou-se de questões fechadas para levantar de forma mais pontual o perfil dos entrevistados. Após essa fase foi organizado um roteiro com perguntas semi-estruturadas, também denominadas perguntas abertas, por permitirem a liberdade de expressão dos entrevistados (MARCONI; LAKATOS, 2004).

Posteriormente, as informações obtidas em campo foram examinadas por meio da análise de conteúdo, a qual consiste em um conjunto de técnicas de análises das comunicações ocorrentes (BARDIN, 2009). Dessa forma, o trabalho de pesquisa tomou vida e 
por meio da voz dos entrevistados foi possível construir o cenário de vivências e convivências e práticas do estágio docente supervisionado em nível de pós-graduação.

\section{A categorização dos dados da pesquisa}

A metodologia da análise de conteúdo proporcionou a categorização dos dados coletados em campo organizando de forma geral o trabalho de acordo com cada entrevistado. Após a realização de cada entrevista, ocorreu a transcrição dos dados e a confecção e montagem de um quadro de falas, que proporcionou a ordenação do trabalho em categorias.

O método de categorização para Bardin significa um método de ordenar a desordem:

É o método das categorias, espécie de gavetas ou rubricas significativas que permitem a classificação dos elementos de significação constitutivos da mensagem. É, portanto um método taxonômico bem concebido para satisfazer os colecionadores preocupados em introduzir uma ordem, segundo certos critérios, na desordem aparente. (BARDIN, 2009, p. 39).

Em um primeiro momento as categorias pensadas foram denominadas de centrais:

Categoria A: o conceito de monitoria na percepção do monitor.

Categoria B: a percepção do monitor em relação à dinâmica relacional durante as práticas de monitoria. Essa categoria foi subdividida em quatro partes periféricas, demonstradas abaixo:

B1: a dinâmica relacional em relação ao professor supervisor de estágio;

B2: a dinâmica relacional em relação a coordenação envolvida no processo de estágio.

B3: a dinâmica relacional em relação aos alunos da graduação;

B4: a dinâmica relacional em relação ao ambiente da monitoria;

Diante das duas categorias centrais, A e B e da subdivisão de B em subcategorias surgiram também, outras duas categorias com o sentido de complementar a pesquisa são elas:

Categoria C: a percepção do monitor em relação ao diálogo.

Categoria D: a ocorrência de feedback nos processos de estágio docente supervisionado.

É importante ressaltar que, nesse recorte em formato de artigo, somente serão apresentados os resultados e discussões das categorias A, B, B1 e B2. As demais categorias B3, B4, C e D não serão abordadas ficando reservadas para um próximo encontro. Essa decisão está baseada na extensão da dissertação de mestrado e no tempo e espaço 
disponibilizados para a escrita dessa publicação, os quais não permitiriam uma apresentação mais aprofundada de todas as fases desenvolvidas na dissertação de mestrado.

A partir da categorização foi realizado o trabalho propriamente dito de análises, inferências e investigações das falas dos entrevistados. A teoria da Complexidade, mesclada à metodologia da Análise de Conteúdo, trouxe para esta fase da pesquisa grande relevância por possuírem características comuns e compartilharem de preceitos similares. A Análise de Conteúdo é reinventada a cada momento, abarca vários métodos e possui regras de bases para ser desenvolvida com rigor teórico e científico (BARDIN, 2009). A Complexidade por sua vez, apresenta um caminho que se faz ao caminhar, traz instrumentos norteadores do pensar bem - os operadores cognitivos - e combina métodos ou estratégias para a resolução de problemas de pesquisa (MORAES; VALENTE, 2008), sem abrir mão do rigor científico.

\section{Os sujeitos da pesquisa}

Os sujeitos da pesquisa foram escolhidos de forma intencional e possuem característica em comum como apresenta o quadro abaixo:

Quadro 1: Síntese da caracterização dos entrevistados

\begin{tabular}{|c|c|c|}
\hline $\begin{array}{l}\text { Quantidade de monitores na listagem oficial } \\
\text { da IES. }\end{array}$ & \multicolumn{2}{|c|}{ Mais de 15} \\
\hline $\begin{array}{l}\text { Quantidade total de monitores } \\
\text { entrevistados. }\end{array}$ & \multicolumn{2}{|c|}{7} \\
\hline Idade dos monitores entrevistados. & \multicolumn{2}{|c|}{ Acima de 30 anos } \\
\hline Área de formação na graduação. & \multicolumn{2}{|c|}{ Todos licenciados } \\
\hline $\begin{array}{l}\text { Distribuição dos entrevistados por área de } \\
\text { concentração no Mestrado em Educação. }\end{array}$ & $\begin{array}{c}5 \\
\text { Políticas e } \\
\text { Administração } \\
\text { Educacional }\end{array}$ & $\begin{array}{c}2 \\
\text { Ensino-Aprendizagem }\end{array}$ \\
\hline Monitores bolsistas da CAPES. & \multicolumn{2}{|c|}{ A minoria } \\
\hline \multirow[t]{2}{*}{$\begin{array}{l}\text { Distribuição dos entrevistados pelo tempo } \\
\text { de realização da monitoria. }\end{array}$} & $\begin{array}{c}4 \\
\text { Um semestre }\end{array}$ & \multirow[t]{2}{*}{$\begin{array}{c}2 \\
\text { Dois semestres }\end{array}$} \\
\hline & $\begin{array}{c}1 \\
\text { Três semestres }\end{array}$ & \\
\hline
\end{tabular}


Foram selecionados sete participantes regularmente matriculados no curso de Mestrado em Educação. Todos são maiores de trinta anos de idade, a maioria realizou as práticas docentes da monitoria por um semestre entre os anos de 2009 e 2010. Alguns foram bolsistas da CAPES. Cinco entrevistados pertencem à área de políticas e administração educacional e dois pertencem à área de ensino-aprendizagem. Todos são graduados em licenciaturas.

\section{O início das entrevistas}

Em relação a dinâmica relacional existente no contexto de monitoria para iniciar as entrevistas foi elaborado um questionário com a finalidade de levantar o perfil de cada entrevistado e sintetizar as informações a respeito dos trabalhos desenvolvidos por eles. Esses dados são apresentados de forma resumida em formato de quadro:

Quadro 2: Síntese dos dados referentes ao estágio docente supervisionado

\begin{tabular}{|l|c|c|c|}
\hline $\begin{array}{l}\text { Realizou a monitoria em qual curso da } \\
\text { graduação? }\end{array}$ & $\begin{array}{c}2 \\
\text { Não sei }\end{array}$ & $\begin{array}{c}1 \\
\text { Não lembro }\end{array}$ & $\begin{array}{c}4 \\
\text { Pedagogia }\end{array}$ \\
\hline $\begin{array}{l}\text { Recebeu informativo/manual escrito a } \\
\text { respeito das normas relacionadas ao } \\
\text { desenvolvimento da monitoria? }\end{array}$ & \multicolumn{3}{|c|}{ Todos responderam não. } \\
\hline $\begin{array}{l}\text { Assinou o termo de compromisso antes } \\
\text { da realização da monitoria? }\end{array}$ & \multicolumn{2}{|c|}{ Todos responderam não. } \\
\hline $\begin{array}{l}\text { Entregou relatório ao final das práticas } \\
\text { da monitoria? }\end{array}$ & \multicolumn{2}{|c|}{ Todos responderam não. } \\
\hline
\end{tabular}

A partir do quadro 2, identifica-se que dois monitores não sabiam em qual curso da graduação realizaram suas práticas de monitoria; um não se lembrava; quatro responderam que realizaram a monitoria no curso de Pedagogia. Nenhum monitor recebeu informativo ou manual escrito a respeito das normas da monitoria; nenhum deles assinou o termo de compromisso, referente às praticas de estágio supervisionado, como exige a Lei de Estágio, antes da realização das práticas docentes supervisionadas ou mesmo entregou relatórios ao final dos trabalhos. As informações a respeito do desenvolvimento da monitoria, de acordo com os monitores, foram passadas apenas oralmente e, segundo a maioria, de maneira superficial e não adequada.

Outro ponto relevante que cabe esclarecer é que as palavras centrais e periféricas não 
denotam, nesse contexto, sentido de superior e inferior, mais importante e menos importante. Apenas serão utilizadas para, didaticamente, ressaltar o centro das análises e o que estava ao seu redor. As inferências, em um primeiro momento, iniciaram-se pelas categorias centrais A e $\mathrm{B}, \operatorname{logo}$ depois adentraram no contexto das categorias periféricas.

\section{Os resultados da categorização}

Categoria A: Os monitores foram entrevistados após o término dos trabalhos de monitoria e durante as entrevistas foi constatado que a maioria entendia o significado de monitoria. De forma geral, eles a definiram como: trabalho de auxílio ao professor; trabalho de assessoria ao professor; trabalho que proporciona suporte ao monitor para o desempenho de tarefas futuras; ponte entre teoria e prática; entre outras. No entanto, um deles afirmou que, quando foi realizar as práticas não entendia muito bem do que se tratava e qual seria o seu papel:

Quando fui [...] participar da monitoria, não entendia muito bem o que que isso representava e muito menos ainda porque não recebi nenhuma orientação. E fiquei perguntando até no caminho quando éé..., estava com a professora [...] afinal qual será o meu papel no trabalho de monitoria? E me diziam: - ah..., você ah..., você fica na sala, observa, olha faz a chamada e é isso ai [...]. (Transcrição da fala do Monitor Y).

Nesse momento ficou claro que as informações e orientações sobre o processo de estágio docente supervisionado, que deveriam ter sido apresentadas e detalhadas antes de o processo ter início, por escrito, em formato impresso ou digital, não foram devidamente esclarecidas para todos os monitores.

Além disso, alguns professores talvez, não possuíssem o perfil adequado para exercer a função de supervisor de estágio, pois demonstram em suas atitudes não compreender com clareza a importância do estágio para quem o realizava. De acordo com as afirmações do monitor T, o estágio realizado perdeu o sentido de ato educativo que o prepararia para, em um futuro próximo, ministrar aulas em nível de graduação tornando-se muito mais um trabalho de auxílio administrativo do que de experiência em docência a ser desempenha em sala de aula:

[...] a gente acompanhava ah..., é..., os professores no caso, é mais auxiliando. Era só uma vez por mês as aulas. Então, a gente ia, auxiliava esse professor durante a aula, mais assim, em questões gerenciais mesmo, entrega de papéis, [...]. Depois, a gente pegava os trabalhos desses alunos, que os professores passavam, e a gente corrigia. Então o trabalho era mais interno do que propriamente externo. Era mais corrigir, lançar notas no sistema [...] não foram práticas muito complexas, ah..., o nosso trabalho era muito operacional, não era assim..., a gente não chegava lá pra dá uma aula. O máximo que a gente fazia mesmo, em questão pedagógica, era em questão 
de explicar alguma atividade (Transcrição da fala do Monitor T).

Em comum acordo com as ideias do monitor $\mathrm{T}$, a autora e pesquisadora Buriolla (2009), afirma que o estágio é um campo de treinamento, um espaço de aprendizagem do fazer concreto. Mais que isso, o estágio docente supervisionado é o momento para que o futuro docente vivencie a realidade do campo de trabalho.

Categoria B: a dinâmica relacional está intimamente relacionada ao contato que os monitores tiveram com os quatro elementos do contexto da monitoria: o professor supervisor, a coordenação, os alunos da graduação e o ambiente em que a monitoria foi desenvolvida.

Eles são diretamente influenciados por esses fatores ao desenvolverem seus trabalhos, pois é o momento em que, ao entrarem em contato com o meio e com os demais atores do estágio partilham e compartilham linguagens, pensamentos e emoções em um processo dinâmico de relações.

Categoria B1: a dinâmica relacional em relação ao professor supervisor segundo a maioria dos entrevistados se desenvolveu de forma pacífica e mesmo que, as atividades desempenhadas pela maioria dos monitores, em sala de aula, tenham sido de secretariar os professores supervisores, a prática da docência supervisionada não ficou ausente de todas as experiências vivenciadas por eles.

Dois monitores afirmaram que tiveram a oportunidade de ministrar uma aula. $\mathrm{O}$ monitor $\mathrm{F}$ informou que foi possível exercer a docência supervisionada, para os alunos da graduação, de maneira integrada com o seu trabalho cotidiano de professor e com o conteúdo de seu trabalho de pesquisa desenvolvido no curso de Mestrado em Educação:

É porque foi a parte que me coube, foi exatamente a simulação de estatística. Então ficou tranquilo porque já era a minha área de trabalho, eu já trabalhava com essa disciplina assim, até na época ainda tava trabalhando na minha pesquisa e até mostrei algumas coisas de dados da minha pesquisa né? [...] algumas coisas eu mostrei e a gente trabalhou com alguns tópicos da estatística. Coisas assim que eles vão precisar porque na graduação eles fazem o TCC [...]. (Transcrição da fala do Monitor F).

Para ele foi uma experiência positiva e gratificante, porém o monitor $\mathrm{K}$ relatou uma vivência um tanto negativa e traumática:

[...] no primeiro semestre foi negativo e traumático porqueeee..., eu sem experiência tive uma reunião com o professor e ele falou assim: - olha na primeira aula você vai me acompanhar, eu vou expor, apresentar você a turma e vou explicar a disciplina pra as pessoas, pros os alunos, eles vão ler um livro e você deve comprar, chamado Política Educacional da Sofia Lerche. Eu disse ok, não, tudo bem..., ele só falou isso, só que eu sou [...] de artes, minha pesquisa foi sobre artes. Políticas e gestão foi algo que eu só tinha estudado na minha graduação, ou seja, há anos atrás. Então, quando eu cheguei no primeiro dia de aula, sorridente, com toda a ingenuidade [...], o professor me apresentou a turma e disse na frente de todos: - agora com você [...] 
tchau... (breve silêncio)... eu fiquei atônita, os alunos perceberam isso, me viram totalmente despreparada..., e lá fui eu tentar explicar o que que era política educacional para os alunos, sem eu mesma ter me lembrado o que que era política educacional, então..., foi umaa..., e isso refletiu durante todo o semestre porque os alunos tiveram uma imagem negativa de mim, então isso foi traumático, nesse aspecto, porque eu passei o semestre inteiro tendo problemas com os alunos que não me respeitavam eee..., até mesmo me achavam sem qualificação para o cargo [...]. (Transcrição da fala do Monitor K).

O livro, ao qual o monitor $\mathrm{K}$ se referiu, é intitulado como Política Educacional no Brasil: introdução histórica, escrito pelas autoras Sofia Lerche Vieira e Isabel Maria Sabino (2007). Após tal depoimento, por meio de uma leitura aprofundada da legislação e do material de estágio fornecido pela instituição não foi encontrada nenhuma referência, mesmo que de maneira implícita, que determinasse que o monitor, para realizar as práticas de monitoria, necessitasse de adquirir, por meio de compra, qualquer tipo de material.

Normalmente, alguns professores supervisores disponibilizam o material a ser trabalho em sala de aula, com antecedência, para que os monitores que realizam as práticas sob sua supervisão possam se preparar.

Outro monitor afirmou que o relacionamento pessoal com a professora que o supervisionava no estágio era tranquilo, porém faltou conhecimento:

É bom. O relacionamento com a professora é bom. Mais o que que é a monitoria? Eu achei que não foi boa. Eu fui com uma outra perspectiva, de ser monitor, o que na verdade não aconteceu. A minha perspectiva era que eu fosse, por exemplo, você vai na semana então, você tem que saber o conteúdo que a professora vai trabalhar. Você tem que tá preparado pra também se alguém te faz uma pergunta, né? Eu não, na verdade eu não sabia, eu não tinha conhecimento de nada [...]. (Transcrição da fala do Monitor Z).

Por meio das transcrições apresentadas percebe-se que o relacionamento pessoal da maioria dos monitores entrevistados foi considerado bom. No entanto, o relacionamento profissional por parte dos professores supervisores de estágio em relação aos monitores sob sua responsabilidade deixou a desejar.

Categoria B2: a dinâmica relacional em relação a coordenação envolvida no processo de estágio foi considerada pela maioria como fragmentada, muitas vezes ausente e realizada de forma diferente para cada grupo.

Nesse caso, cabe relembrar que a instituição pesquisada possui duas coordenações responsáveis pelo estágio docente supervisionado. Uma situada no campus da pós-graduação, denominada de Grupo de Pesquisa (GP). A outra está situada no campus dos cursos de graduação, localizada no espaço destinado ao curso de Pedagogia a qual, desenvolve o 
trabalho de estágio com o nome Grupo de Aprendizagem (GA).

Embora ambas recebam os estudantes do curso de mestrado para a realização das atividades, a monitoria é tratada de forma diferente como afirma o monitor $\mathrm{T}$ :

Eu que participei dos dois, o GP é totalmente fragmentado, o GA é uma parceria. Eu encaro como uma parceria. [...] No GA, eu já planejei com a professora n vezes. [...] tenho meu diário, é..., eu tenho um caderninho que eu anoto quem faz e quem não faz. Eu corrijo atividades de sala dela, [...] O GP é totalmente fragmentado. [...] embora sejam o mesmo enfoque no caso ou gestão ou ensino aprendizagem. São aulas estanque. [...] Pra mim não tem uma sequência, [...] acaba ficando meio perdido e gera muita dúvida [...] O GA é muito mais sistematizado. Eu não sei se é porque já é o professor da grade ali da graduação. O GP também tem essa questão de ser o professor é..., aqui da pós [...], então até isso eu acho que fica meio..., meio solto. É pra mim GA e GP são totalmente diferentes. [...].(Transcrição da fala do Monitor T).

Por meio da fala do monitor T, ao informar a divisão entre as coordenações de estágio da pós-graduação e da graduação, percebe-se a fragmentação nas ações administrativas da instituição em relação ao processo de estágio docente supervisionado. Não existe um planejamento em conjunto das coordenações responsáveis pelos trabalhos embora, as duas tenham o mesmo objetivo.

As demais categorias ficaram reservadas para um próximo encontro. As informações apresentadas até o momento já se fazem mais que suficiente para a construção de inferências análises e posicionamentos em relação ao tema.

\section{Os diálogos, as percepções e as inferências da pesquisa}

O ponto de partida da Análise de Conteúdo é a mensagem (FRANCO, 2008), por meio da qual o analista tece concepções críticas e faz inferências baseadas tanto no aporte teórico quanto em suas vivências. O início da fase de resultados e discussões evidencia o perfil dos entrevistados e traz as suas percepções em relação ao campo de monitoria. Posteriormente, aborda em formato de categorias, as informações adquiridas, através dos dados das entrevistas semiestruturadas, embasam a construção do texto escrito que como uma colcha de retalhos é tecida pouco a pouco.

A listagem de monitores que haviam concluído a vivência de estágio docente supervisionado apresentada pela coordenação de estágios GP da IES, continha mais de quinze estagiários. Porém, devido aos critérios estabelecidos para a realização da pesquisa como, por exemplo, a matrícula regularmente instituída e o término das atividades de estágio, foram 
selecionados quinze estudantes e desses, somente sete aceitaram participar da pesquisa.

Um ponto a ser observado foi a dificuldade que alguns estagiários entrevistados demonstraram, em começar a relatar os fatos ocorridos, devido ao medo de perseguição por parte de professores supervisores e coordenadores da IES. O entrevistado X disse: - “... você tem certeza que não tem como descobrirem a gente? Já pensou se eles pegam a lista e veem lá o meu nome! Ai eu tô enrolad..." (Risos nervosos). Meu Deus!". O entrevistado Z também demonstra desconfiança para contar: "Você me chamou aqui pra falar, eu posso falar a verdade? (Tom desafiador e incrédulo). Você tem certeza disso? Porque eu vou falar a verdade."

As transcrições das entrevistas abordadas na Categoria A trazem questões relevantes que chamam atenção para a dimensão legislativa do estágio no Brasil. A maioria dos estagiários, apesar de possuírem uma visão fundamentada a respeito do conceito de monitoria, no decorrer das entrevistas deixou claro que não sabiam o que ela realmente significava que, não foram repassadas as informações e orientações de forma adequada e que, em muitos casos, não foram repassadas nenhum tipo de orientação de como seria o processo de estágio no campo em que desenvolveriam as atividades.

Esse fato aponta para a irregularidade dos procedimentos de estágio supervisionado ofertado pela IES. Algumas questões deverão ser repensadas já que os problemas não se apresentam apenas na falta de comunicação a respeito de como seria o desenvolvimento do processo de estágio entre a IES e os estudantes, mas também, em relação aos documentos legais exigidos pela Lei de Estágio.

A Lei de Estágio em seu art. $3^{\circ}$, inciso II, impõe a celebração do Termo de Compromisso entre o educando, a parte cedente do estágio e a instituição de ensino (BRASIL, 2008). Nesse caso, a parte cedente do estágio e a instituição de ensino são a mesma pessoa, porém isso não excluiu a obrigação de assinatura desse documento.

O momento de assinatura do Termo de Compromisso, entre as partes envolvidas no processo de estágio, deverá ocorrer antes do início das práticas e também, oportuniza a comunicação entre as partes, os esclarecimentos, as informações, as orientações, e a entrega de materiais ao estudante que realizará o estágio supervisionado.

De acordo com a fala dos monitores $\mathrm{Y}$ e $\mathrm{T}$, o estágio foi tratado diretamente com a professora supervisora da prática. Assim, infere-se que, depois dos trabalhos desenvolvidos em campo, é que o processo foi regularizado na coordenação responsável. Esse fato 
caracteriza uma falha da instituição em coordenar os processos de prática supervisionada de seus estudantes.

O estágio supervisionado poderá habilitar o estudante para a vida profissional. É um período de experiência prévia das ações vivenciadas no mercado de trabalho que integra a teoria acadêmica à prática. Porém, é uma atividade controlada e o não cumprimento das determinações da Lei de Estágio implica vínculo empregatício do educando com a parte concedente de estágio, sujeitando-os às normas e penalidades da legislação trabalhista e previdenciária vigentes no país.

A partir da Categoria B por meio dos dados transcritos é possível inferir que a dinâmica relacional em sua dimensão pessoal foi satisfatória. No entanto, a maioria dos monitores afirmou que a parte profissional deixou a desejar. Muitos se sentiram perdidos e sem noção do que aconteceria no estágio.

Outros se ressentiram da falta do trabalho administrativo da IES, do apoio pedagógico adequado dos supervisores do estágio e da clareza em relação ao papel do monitor ao desempenhar as atividades de monitoria. Nesse sentido, infere-se da fala dos entrevistados que o acolhimento profissional por parte dos professores supervisores de estágio em relação aos monitores sob sua responsabilidade deixou a desejar.

A formação técnico-profissional, a que se refere a Lei de Estágio, se caracteriza por atividades teóricas e práticas, metodicamente organizadas em tarefas de complexidade progressiva desenvolvidas no ambiente de trabalho. Além disso, de acordo com o seu artigo $1^{\circ}$, parágrafo $1^{\circ}$ e $2^{\circ}$, as práticas a serem desenvolvidas deverão fazer parte do projeto pedagógico do curso, visando ao aprendizado de competências próprias da atividade profissional (BRASIL, 2008).

A minoria dos estagiários entrevistados vivenciou a oportunidade de ministrar aulas em nível de graduação e a maioria vivenciou suas práticas reduzidas apenas ao auxílio administrativo do professor supervisor de estágio como, por exemplo, os lançamentos de notas no sistema da IES. Nesse caso, a realização do estágio docente supervisionado perdeu o sentido, pois de acordo com a Portaria n ${ }^{\circ}$ 64/2002, da CAPES, em seu artigo 22, o estágio na pós-graduação objetiva a preparação para a docência.

Cada profissão possui características e necessidades particulares desenvolvidas de acordo com as respectivas áreas de trabalho. Os estágios devem ser pensados e organizados para atender a essas particularidades e, obrigatoriamente, devem seguir características 
comuns, determinadas pela legislação federal.

Nesse cenário constata-se também que a dinâmica relacional abordada na dimensão da coordenação do estágio docente supervisionado deixou a desejar. A estrutura fragmentada com duas coordenações de estágio, uma na pós-graduação e outra na graduação, com procedimentos diferentes e não interligados são fatores a ser repensados pela IES. Em âmbito específico, a atuação da coordenação da pós-graduação tanto em relação aos estudantes estagiários, como em relação aos professores designados para supervisionar o estágio foi insuficiente e em muitos momentos se apresentou ausente.

A Complexidade pode ser definida como aquilo que é tecido junto confeccionado de modo sistemático como uma teia, os acontecimentos, ações, interações, retroações, determinações, acasos que constituem o mundo fenomênico (MORIN, 2007). Por esse viés, a construção de um trabalho em rede, integrado, de trocas, de múltiplas ações e comunicações entre as coordenações de estágio apresentadas poderia ser um ponto de reflexão.

Outro ponto a ser refletido está no princípio da ética, o qual se revela no respeito pelo outro, na solidariedade, na cooperação e na preservação de uma cultura comum a todos (MORAES, 2008). A cultura do estágio docente supervisionado que ao trabalhar a possibilidade da união entre a teoria e prática proporcione uma ação e atuação pedagógica aberta, acolhedora, integradora, desenvolvida de forma humanizada.

\section{As considerações finais provisórias}

Os objetivos pretendidos por este artigo foram atingidos. A dinâmica relacional estabelecida no desenvolvimento das práticas de ensino docente supervisionado, de acordo com a percepção de alunos estagiários da pós-graduação é de natureza complexa. Por meio desse recorte do trabalho de dissertação de mestrado é possível levar os resultados para diversas pessoas e, assim contribuir para a sociedade de forma geral. Além disso, ampliar os debates e incentivar novas pesquisas.

A escolha do conjunto de métodos e técnicas como: a abordagem qualitativa de caráter exploratório, a técnica de entrevista semiestruturada, a metodologia da Análise de Conteúdo e a metodologia trazida pela teoria da Complexidade, formaram um tecido instrumental harmônico, flexível, aberto, consistente de rigor científico, o qual originou o texto escrito da pesquisa e desse artigo. 
A monitoria consiste em um trabalho voluntário, por meio do qual o aluno-monitor acompanha o professor-supervisor nas atividades práticas desenvolvidas presencialmente em sala de aula. Mais que isso, consiste em uma oportunidade de crescimento, de observação, de ensaio da prática, de contato com o meio e com os atores do contexto. É a chance de aprender, de receber e doar informações, de construir os próprios caminhos da aprendizagem, a partir da observação in loco.

O estágio docente supervisionado deverá proporcionar, àquele que o vivencia, a possibilidade de extrair desse ambiente, por meio do contato com os atores e com a estrutura de forma geral, as informações, as impressões da dinâmica relacional, como um todo, para que sejam organizadas, transformando-se em conhecimentos.

Como afirma Morin (2007), o sujeito, por meio da comunicação com os demais, tem a capacidade de extrair do meio as informações, transformando-as em conhecimento. O estágio em licenciatura faz parte desse contexto, é um momento especial, pois deverá preparar futuros educadores, profissionais da Educação, cidadãos humanos e humanizadores, com compromisso social, ético de colaborar na formação de outras pessoas que por sua vez, poderão contribuir na formação de mais outras pessoas.

Cabe ressaltar que é preciso uma reflexão sistemática sobre os processos ocorridos no campo de estágio da IES pesquisada, pois tanto o ensino como a aprendizagem em nível de estágio docente supervisionado se encontram comprometidos. Existe um nítido descompasso entre a legislação apresentada, as ideias trazidas pelos autores e a realidade de estágio docente supervisionado em nível de pós-graduação vivenciada e expostas pelos monitores.

É necessária a mudança, um repensar, uma reordenação para a elaboração e para o desenvolvimento de ações integradas e coerentes, que possam vir a apoiar e a orientar os monitores e os professores supervisores da monitoria. Para que essa mudança seja efetivada, sugere-se aqui, a reordenação de todo o contexto, a elaboração de uma nova lógica de trabalho, não fragmentada, não individualizadora.

Dessa forma, com base nas considerações e afirmações de Moraes (2008) e de Morin (2010a; 2010b), foi possível elaborar quatro diretrizes norteadoras para uma nova construção de monitoria: trabalho integrado e integrador dos sujeitos, abertura, flexibilidade e contextualização do conhecimento.

O primeiro passo, mais por uma ordem didática do que efetivamente uma regra, seria o desenvolvimento de um trabalho integrado e integrador, não fragmentado e não 
individualizador. Para proporcionar a vivência de uma formação docente, em nível de pósgraduação, multidisciplinar que unisse o trabalho desempenhado em campo pelos monitores com a sua área de formação. O trabalho integrado diz respeito, também, às ações da coordenação e do professor supervisor, os quais, juntos, com informações padronizadas e por meio de uma rede de comunicação efetiva, apoiassem os monitores de maneira acolhedora, desde o início das práticas até o recebimento do certificado de monitoria.

O segundo passo seria uma abertura à escuta sensível, à importância da valorização das vivências e experiências de cada indivíduo, que não podem ser excluídas do contexto das práticas docentes. Como afirma Moraes (2008), abertura em relação às maneiras de aprender, trabalhando com uma metodologia não-fechada de construção do conhecimento.

Em terceiro plano, sugere-se a flexibilidade de olhar o outro e de compreender as diferenças, entender que cada indivíduo tem seu tempo individual, único, de processos de aprendizagem. $\mathrm{O}$ educador deve ser mediador e flexível às emergências, às mudanças, aos processos de organização e auto-organização daqueles que são mediados por ele.

A quarta sugestão é a contextualização das informações para que a aprendizagem possa fazer sentido. É tornar o conhecimento construído, significativo e pertinente. É certo que ainda poder-se-ia abordar a ética nas ações, o trabalho em rede, a multireferencialidade e, tantas outras diretrizes, trazidas pela teoria da Complexidade que, de forma harmônica, aplicadas ao contexto da monitoria pesquisada, poderiam transformá-la. Porém, esse assunto se faz digno de um novo trabalho, de um novo projeto. Para tanto, é necessário maiores aprofundamentos teóricos, epistemológicos, de novas perspectivas a serem desenvolvidas em um momento futuro.

\section{Referências bibliográficas}

ALBERTI, Verena. Manual de história oral. 3. ed. Rio de Janeiro: Editora FGV, 2005.

ALVES-MAZZOTTI, Alda Judith; GEWANDSZNAJDER, Fernando. O método nas ciências naturais e sociais: pesquisa quantitativa e qualitativa. São Paulo: Pioneira, 1998.

BARDIN, Laurence. Análise de conteúdo. Lisboa - Portugal: Edições 70, 2009.

BIANCHI, Ana Cecilia de Moraes; ALVARENGA, Marina; BIANCHI Roberto. Orientação para estágio em licenciatura. São Paulo: Pioneira Thomson Learning, 2005. 
BRASIL. Lei $\mathbf{n}^{0} \mathbf{1 1 . 7 8 8}$, de 25 de setembro de 2008. Dispõe sobre o estágio de estudantes; altera a redação do art. 428 da Consolidação das Leis do Trabalho - CLT, aprovada pelo Decreto-Lei $n^{\circ} 5.452$, de $1^{\circ}$ de maio de 1943, e a Lei $n^{\circ}$ 9.394, de 20 de dezembro de 1996; revoga as Leis ns 6.494, de 7 de dezembro de 1977, e 8.859, de 23 de março de 1994, o parágrafo único do art. 82 da Lei n ${ }^{\circ} 9.394$, de 20 de dezembro de 1996, e o art. $6^{\circ}$ da Medida Provisória $n^{\circ}$ 2.164-41, de 24 de agosto de 2001; e dá outras providências. Disponível em: <www.planalto.gov.br/ccivil_03/_ato2007-2010/2008/lei/11788.htm>. Acesso em: 22.dez.2010.

Ministério da Educação. Coordenação de Aperfeiçoamento de Pessoal de Nível Superior (CAPES). Portaria $\mathbf{n}^{\mathbf{0}}$ 64, de 18 de novembro 2002. Aprovar o novo Regulamento do Programa de Fomento à Pós-Graduação, constante do anexo a esta Portaria. Disponível em: <http://www.capes.gov.br/images/stories/download/relatorios/Regulamento.pdf>. Acesso em: 14.set.2010.

BURIOLLA, Marta Alice Feiten. O estágio supervisionado. 6. ed. São Paulo: Cortez, 2009.

FURLANETO, Ecleide Cunico. Como nasce um professor? Uma reflexão sobre o processo de individualização e formação. 4. ed. São Paulo: Paulus, 2007.

FRANCO, Maria Laura Puglisi Barbosa. Análise de Conteúdo. Brasília: Liber Livro Editora, 2007.

MARCONI, Marina de Andrade; LAKATOS, Eva Maria. Fundamentos da metodologia científica. 7 ed. São Paulo: Atlas, 2010.

MORAES, Maria Cândida. Ecologia dos saberes: complexidade, transdisciplinaridade e educação: novos fundamentos para iluminar novas práticas educacionais. São Paulo: Antakarana/WHH - Willis Harmam House, 2008.

MORAES, Maria Cândida; VALENTE, José Armando. Como pesquisar em educação a partir da complexidade e da transdisciplinaridade? São Paulo: Paulus, 2008.

MORIN, Edgar. Ciência com consciência. Tradução de Maria D. Alexandre e Maria Alice Sampaio Dória. 13 ed. Rio de Janeiro: Bertrand, 2010a.

. Meu Caminho: entrevistas com Djénane Kareh Tager. Tradução de Edgar Assis Carvalho e Mariza Perassi Bosco. Rio de Janeiro: Bertrand Brasil. 2010b.

Introdução ao pensamento complexo. Tradução de Eliane Lisboa. 3 ed. Porto Alegre: Sulina, 2007.

MORIN, Edgar, CIURANA, Emilio-Roger, MOTTA, Raúl Domingo. Educar na era planetária: o pensamento complexo como método de aprendizagem no erro e na incerteza humana. Tradução de Sandra Trabucco Valenzuela. 3 ed. São Paulo: Cortez. 2009.

PICONEZ, Stela Conceição Bertholo. A prática de ensino e o estágio supervisionado. (Coord.) 18 ed. Campinas, SP: Papirus, 2010. 
PIMENTA, Selma Garrido. O estágio na formação de professores: unidade entre teoria e prática. Caderno de Pesquisa, São Paulo, n. 94, p. 58-73, ago. 1995. Disponível em: $<$ http://www.inep.gov.br/pesquisa/bbeonline/obras.asp?autor=PIMENTA,+SELMA+GARRIDO>. Acesso em: 27. fev. 2011.

QUEIRÓZ, Maria Isaura Pereira de. O pesquisado, o problema da pesquisa, a escolha de técnicas: algumas reflexões. In: LANG, A. B. S. (Org.). Reflexões sobre a pesquisa sociológica. São Paulo: Centro de Estudos Rurais e Urbanos, 1992. p. 13-29. (Coleção Textos; $2^{\mathrm{a}}$ série, 3 ). 